\title{
Numerical Study on Optimization of Structural Parameters of Guiding Vane of Longitudinal Ventilation for Highway Tunnel
}

\author{
Shixian Wu, ${ }^{1,2}$ Heqing Liu, ${ }^{1}$ Yongping Chen $\mathbb{D D}^{2}{ }^{2}$ and Haiqiao Wang ${ }^{1}$ \\ ${ }^{1}$ School of Resource, Environment and Safety Engineering, Hunan University of Science and Technology, Xiangtan 411201, \\ Hunan, China \\ ${ }^{2}$ Department of Building Environment and Energy Engineering, Guilin University of Aerospace Technology, \\ Guilin 541004, Guangxi, China \\ Correspondence should be addressed to Yongping Chen; 173422623@qq.com
}

Received 4 July 2018; Accepted 5 September 2018; Published 3 October 2018

Guest Editor: Dengke Wang

Copyright () 2018 Shixian Wu et al. This is an open access article distributed under the Creative Commons Attribution License, which permits unrestricted use, distribution, and reproduction in any medium, provided the original work is properly cited.

\begin{abstract}
In order to reduce the energy loss during longitudinal ventilation for highway tunnels, a guiding vane was proposed to be installed on the tunnel dome in the downstream of the air supply outlet. The effects of the guiding vane's angles and equivalent heights on the effectiveness of tunnel ventilation were investigated by the numerical simulation using the CFD approach. When the installation angle of the guiding vane was $2 \sim 5$ degrees and the equivalent height was $0.20 \sim 0.35$, the guiding vane played a significant role in drag reduction. Under the circumstances, the pressure-rise of air supply outlet was the maximum. The required distance for pressure-rise was approximately $90 \sim 115 \mathrm{~m}$ that was not affected by the average air velocity in the tunnel and the structure parameters of the guiding vane.
\end{abstract}

\section{Introduction}

Tunnel ventilation systems are needed to maintain air quality to ensure the safety of personnel in the tunnel [1-4]. In recent years, the application of shaft blowing and exhausting longitudinal ventilation systems in highway tunnels has significantly increased. However, high-energy consumption in the ventilation systems has always been a difficulty that limits the development of tunnel engineering.

Researchers have been focusing on the optimization of ventilation equipment and local structures in the ventilation systems. For instance, efforts have been made to optimize the structure of flow field in tunnels by optimizing fan distance, air supply angle, and the parameters of local geometry in order to reduce ventilation resistance and thus the operation costs of the ventilation systems. Basing on an experimental study, Ishida [5] found that installation of an air deflector at the outlet of the fan could improve pressure regulation of the jet fan. A series of experimental studies on the longitudinal ventilation system were conducted by Pavesi et al. [6], and they concluded that the high velocity of the jet flow, the friction loss on the wall of tunnel, and the vortex loss nearfan were the main factors of the decrease of the efficiency of jet fan. According to a numerical study using the CFD approach, Betta et al. and Lee et al. [7-9] found that the friction loss between the airflow and the top wall of tunnel could be reduced when the inlet and outlet of the jet fan were installed at the optimum angle. Fan et al. [10] proposed that the pressure-rise effect of the jet fan was related to the position of the fan, and they obtained the optimum longitudinal and horizontal distances of the jet fan. Wang et al. [11-13] conducted comprehensive analysis on the characteristics of the jet flow for a special curved highway tunnel through numerical simulation. They concluded it with an optimum installation angle of 3 degrees. It is also pointed out that the optimum installation angle and distance of the jet fan in a curved highway tunnel were remarkably different than that in a straight one. Shi and Xia [14] performed numerical analysis for the optimization of flow field in the short duct of the highway tunnel and concluded that the 
optimum length of short duct was in the range of $65-80 \mathrm{~m}$. Zhang et al. [15] established the formula to precisely predict the local loss of the bifurcation tunnel with an angle from 5 to 15 degrees basing on laboratory experiments and numerical simulation. Li et al. [16] stated that the use of an 80 degree-bent air duct could be as an alternative for a straight curved air duct with guiding vane installed in order to solve the problem of curve vortex losses in tunnel ventilation systems.

However, it lacks of the study on the optimization and improvement of the tunnel flow field structure of the downstream of air supply outlet in the shaft blowing and exhausting longitudinal ventilation system. In general, the air supply outlet of the ventilation system is located at the tunnel dome, and the average air velocity at the air supply outlet can be as high as $25-30 \mathrm{~m} / \mathrm{s}$ [17]. In comparison, the air velocity in the tunnel short duct is much smaller. Therefore, it is more feasible to form a wall-attached jet in the tunnel short duct, leading to substantial losses of wall friction and vortex. In this study, a guiding vane was proposed to be installed on the tunnel dome in the shaft blowing and exhausting longitudinal ventilation systems to optimize the flow field structure of the tunnel. The effects of installation angles and equivalent heights on the ventilation energy consumption were investigated by numerical simulation using the CFD approach to determine the optimum structure parameters of the guiding vane. This study will shed light on the design of ventilation system for highway tunnels.

\section{Model Development}

2.1. Model Description. The cross section of an extra-long highway tunnel is shown in Figure 1. The tunnel has a width of $13.69 \mathrm{~m}$ and a height of $8.46 \mathrm{~m}$. The area of the cross section of the tunnel is approximately $97.18 \mathrm{~m}^{2}$. The hydraulic diameter $\left(D_{\mathrm{t}}\right)$ is $10.06 \mathrm{~m}$, and the height of the air supply outlet is $1.8 \mathrm{~m}$.

Based on the original structure of the longitudinal ventilation system, a guiding vane was installed on the dome at the downstream of the air supply outlet. Figure 2 presents the schematic of installation of guiding vane in the local shaft blowing and exhausting longitudinal ventilation system. Parameters of the local longitudinal ventilation system are shown in Figure 3.

The guiding vane was symmetrical at two ends of the tunnel, and it had an angle of $\alpha$ with respect to longitudinal direction of the tunnel. The distance between the lowest point of the guiding vane and the dome of the tunnel was defined as $h$, and the air supply outlet was located at $X=60 \mathrm{~m}$. Considering the influence distance of the pressurerise generated by the air supply outlet and the stability of the flow field, the length of the tunnel was set as $300 \mathrm{~m}$. The length of the upstream section of air supply outlet was $60 \mathrm{~m}$, and the length of the section in the downstream was $240 \mathrm{~m}$.

2.2. Mesh. The accuracy of the simulation is affected by the number of cells in the model and the step size when

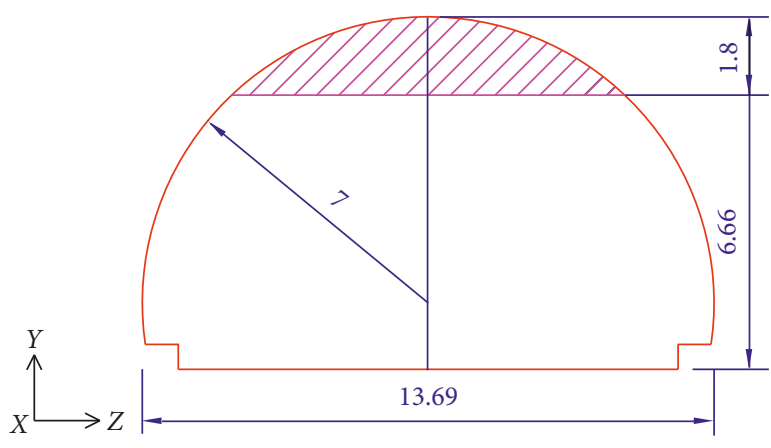

Figure 1: Cross section of the tunnel.

performing numerical analyses on air flow and other issues for tunnels. In this study, three different sizes of mesh (A, B, and C) were adopted as shown in Table 1 . The differences of the static pressure and velocity distribution in tunnel were used to assess the advantages and disadvantages of different mesh sizes. Figure 4 shows static pressure profiles at different positions at $X$-axis with the average air velocity of the tunnel short duct $u=2 \mathrm{~m} / \mathrm{s}$. Figure 5 shows velocity profiles at different positions at $Z$-axis with the average velocity of the tunnel short duct $u=2 \mathrm{~m} / \mathrm{s}, X=100 \mathrm{~m}$, and $Y=0.5 \mathrm{~m}$. As shown in Figure 4, the results obtained by the three mesh sizes were the same, and there was almost no difference in the distribution of the static pressure. However, in Figure 5, the velocity at different positions at $Z$-axis by mesh $\mathrm{A}$ was significantly different from meshes B and C. The discrepancy was much less between mesh B and mesh C. Consequently, mesh $B$ was selected in the model for achieving relatively high calculation accuracy and efficiency.

2.3. Governing Equations. In recent years, the Standard $k-\varepsilon$ turbulence model of CFD has been effectively verified, and it has been widely used in the analyses of ventilation for tunnels. In this study, the standard $k-\varepsilon$ turbulence model was adopted to simulate the flow field for tunnels [18-20]. The governing equation of the fluid flow can be expressed as the follows:

(1) Incompressible continuity equation:

$$
\frac{\partial \rho \bar{u}_{i}}{\partial x_{i}}=0
$$

(2) Incompressible momentum equation:

$$
\frac{\partial\left(\rho \bar{u}_{i} \bar{u}_{j}\right)}{\partial x_{i}}=-\frac{\partial p}{\partial x_{i}}+\frac{\partial}{\partial x_{i}}\left[\mu\left(\frac{\partial \bar{u}_{i}}{\partial x_{j}}+\frac{\partial \bar{u}_{j}}{\partial x_{i}}\right)\right]-\frac{\partial\left(\rho \bar{u}_{i}^{\prime} \bar{u}_{j}^{\prime}\right)}{\partial x_{j}} .
$$

(3) Standard $k-\varepsilon$ turbulence model:

$$
u_{\mathrm{t}}=\rho C_{\mu} \frac{k^{2}}{\varepsilon} .
$$




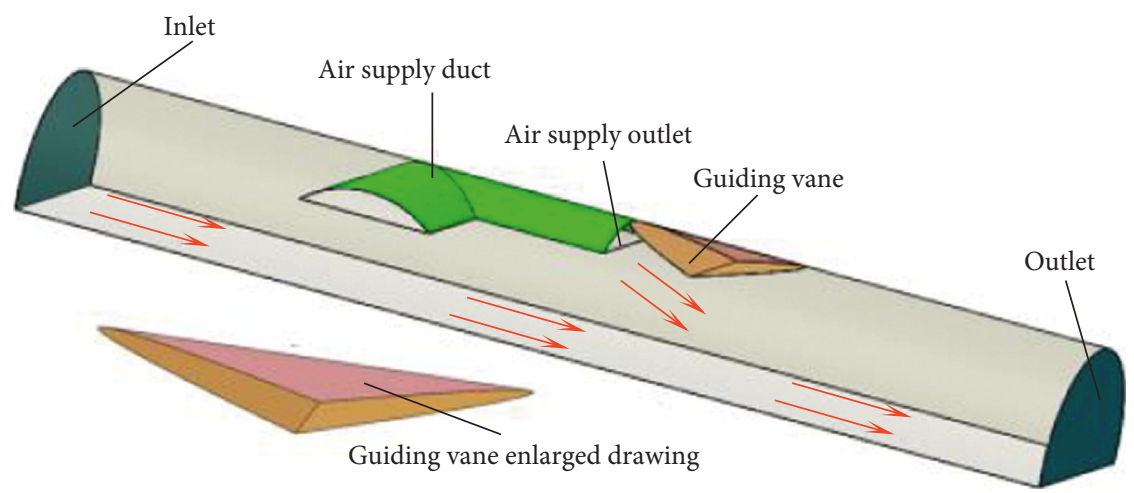

FIgURE 2: Schematic of installation of guiding vane in the local shaft blowing and exhausting longitudinal ventilation system.

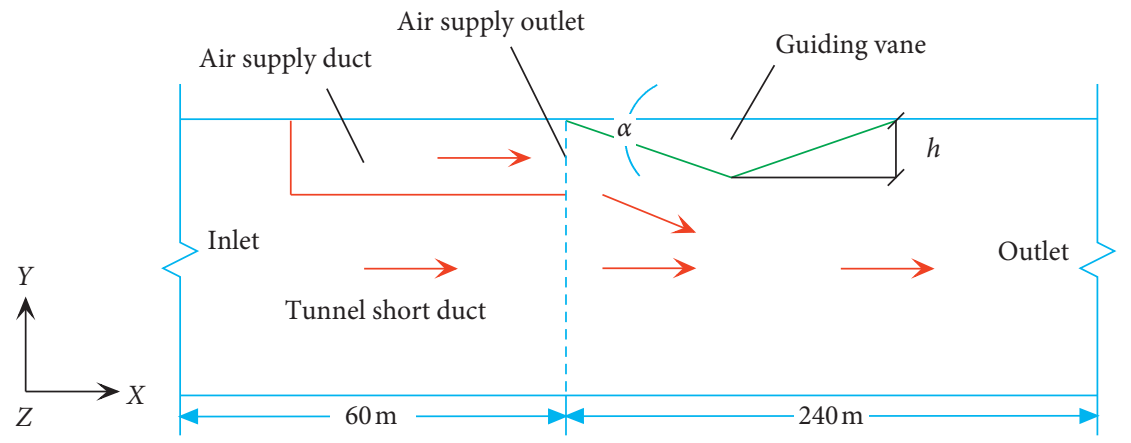

Figure 3: Parameters of the shaft blowing and exhausting longitudinal ventilation system.

TABLE 1: Description of mesh in modeling.

\begin{tabular}{lccc}
\hline Mesh type & A & B & C \\
\hline Total number of cells & 657333 & 917184 & 1411810 \\
\hline
\end{tabular}

(4) $k$ equation:

$\bar{u}_{j} \frac{\partial k}{\partial x_{j}}=\frac{1}{\rho} \frac{\partial}{\partial x_{j}}\left[\left(\frac{\mu_{t}}{\sigma_{k}}+\mu\right) \frac{\partial k}{\partial x_{j}}\right]+\frac{u_{\mathrm{t}}}{\rho}\left(\frac{\partial \bar{u}_{i}}{\partial x_{j}}+\frac{\partial u_{j}}{\partial x_{i}}\right) \frac{\partial \bar{u}_{i}}{\partial x_{j}}-\varepsilon$

(5) $\varepsilon$ equation:

$$
\begin{aligned}
\bar{u}_{j} \frac{\partial \varepsilon}{x_{j}}= & \frac{1}{\rho} \frac{\partial}{\partial x_{j}}\left[\left(\frac{\mu_{\mathrm{t}}}{\sigma_{\varepsilon}}+\mu\right) \frac{\partial \varepsilon}{\partial x_{j}}\right] \\
& +\frac{C_{1} \mu_{\mathrm{t}} \varepsilon}{\rho k}\left(\frac{\partial \bar{u}_{i}}{\partial x_{j}}+\frac{\partial \bar{u}_{j}}{\partial x_{i}}\right) \frac{\partial \bar{u}_{i}}{\partial x_{j}}-C_{2} \frac{\varepsilon^{2}}{k},
\end{aligned}
$$

where $\rho$ is the fluid density, $\mathrm{kg} / \mathrm{m}^{3} ; u_{i}$ and $u_{j}$ are the velocity components of the fluid, respectively, $\mathrm{m} / \mathrm{s} ; u_{i}^{\prime}$ and $u_{j}^{\prime}$ are the corresponding fluctuation component, $\mathrm{m} / \mathrm{s} ; \varepsilon$ is the pressure on the fluid microelement, $\mathrm{Pa} ; \mu$ is the dynamic viscosity, $\mathrm{Pa} \cdot \mathrm{s} ; \mu_{\mathrm{t}}$ is the turbulent viscosity, $\mathrm{Pa} \cdot \mathrm{s} ; k$ is the turbulent kinetic energy, $\mathrm{m}^{2} / \mathrm{s}^{2} ; \varepsilon$ is the dissipation rate, $\mathrm{m}^{3} / \mathrm{s} ; \sigma_{k}$ and $\sigma_{\varepsilon}$ are the Prandtl numbers corresponding to the $k$ and $\varepsilon$ equations, respectively. Based on the previous

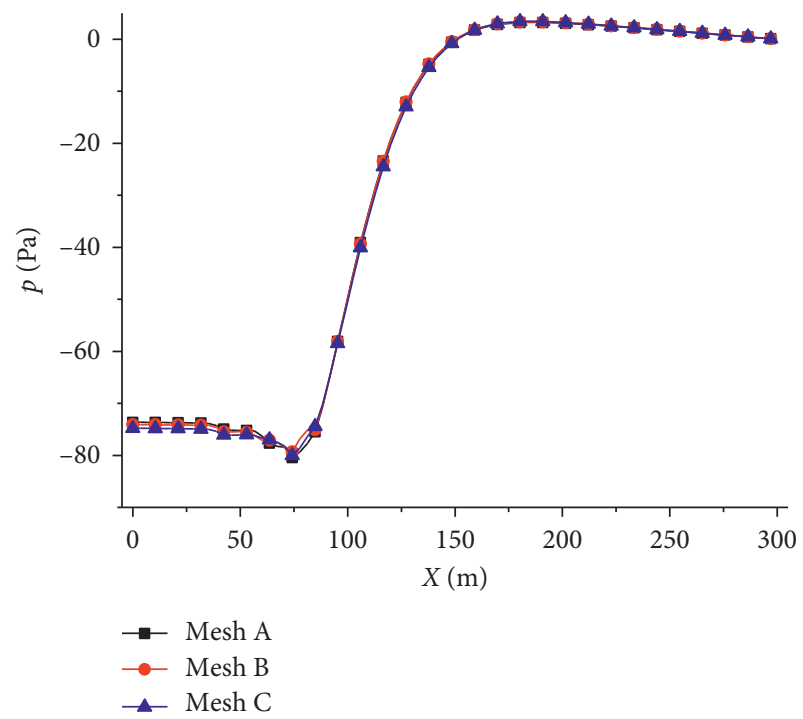

Figure 4: Static pressure profiles at different positions at $X$-axis for different mesh sizes.

experimental results, the values of coefficients in above equations are suggested as $C_{\mu}=0.09, C_{1}=1.44, C_{2}=1.92$, and $\sigma_{\varepsilon}=1.3$.

2.4. Boundary Conditions. The tunnel short duct inlet was set as the boundary of velocity inlet with the average air velocity $u=1 \mathrm{~m} / \mathrm{s}, 2 \mathrm{~m} / \mathrm{s}$, and $3 \mathrm{~m} / \mathrm{s}$ respectively. The tunnel outlet was set as the boundary of the pressure outlet. The air 


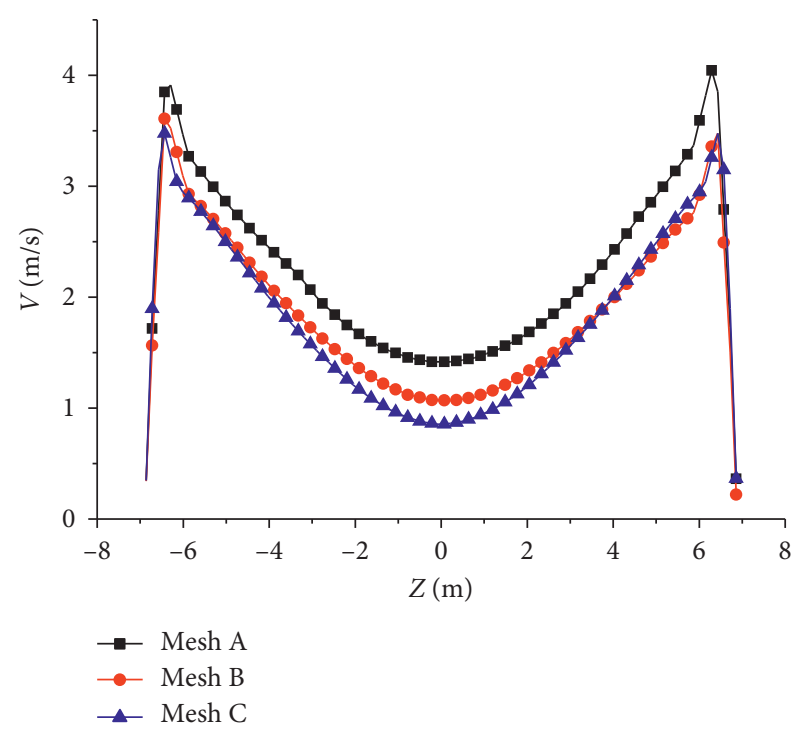

Figure 5: Velocity profiles at different positions at $Z$-axis for different mesh sizes.

supply outlet was set as the boundary of velocity inlet, and the average air velocity was $30 \mathrm{~m} / \mathrm{s}$. The standard nonslip stationary wall boundary condition was applied on the wall of the tunnel.

\section{Results and Discussion}

In this study, the structural parameters of the guiding vane in the model are shown in Table 2 . It is noted that $h_{\mathrm{t}}$ is the equivalent height of the guiding vane, and $h_{\mathrm{t}}=h / D_{\mathrm{t}}, h$ is the height, $D_{\mathrm{t}}$ is the hydraulic diameter of the cross section of tunnel, $h_{\mathrm{tc}}$ is the critical equivalent height of the guiding vane, and $\alpha$ is the installation angle of the guiding vane. Under the same working conditions, the greater the difference of static pressure between the inlet and outlet of the tunnel is, the higher the pressure-rise of the air supply outlet will be. The difference of the static pressure can be expressed as $\Delta p=p_{\text {out }}-p_{\text {in }}$, where $p_{\text {out }}$ is the static pressure at the tunnel outlet and $p_{\text {in }}$ is the static pressure at tunnel short duct inlet.

\subsection{Installation Angle of Guiding Vane and Pressure-Rise.} Figure 6 shows the relationships between $\Delta p$ and $\alpha$ for various $h_{\mathrm{t}}$. It is noted that the average air velocity at the tunnel short duct inlet were $u=1 \mathrm{~m} / \mathrm{s}, 2 \mathrm{~m} / \mathrm{s}$, and $3 \mathrm{~m} / \mathrm{s}$, respectively. It is indicated that the difference of the static pressure changed parabolically with $\alpha$. When the equivalent height of the guiding vane $h_{\mathrm{t}}<0.35$ and the installation angle of the guiding vane $\alpha=2^{\circ} \sim 5^{\circ}$, a peak value of the difference of the static pressure was clearly observed and denoted as $\Delta p_{\mathrm{e}}$. As the equivalent height of the guiding vane increased, $\Delta p_{\mathrm{e}}$ increased as shown in Figure 6(a). For example, when $h_{\mathrm{t}}=0.15, \Delta p_{\mathrm{e}}=97.33 \mathrm{~Pa}$, and when $h_{\mathrm{t}}=0.3, \Delta p_{\mathrm{e}}=111.16 \mathrm{~Pa}$. Meanwhile, as $h_{\mathrm{t}}$ increased, the angle of the guiding vane $\alpha_{\mathrm{e}}$ corresponding to the peak value also increased. For example, when
TABLE 2: Parameters in the model.

\begin{tabular}{lcc}
\hline Case & $h_{\mathrm{t}}$ & $\alpha\left(^{\circ}\right)$ \\
\hline 1 & 0.025 & $0 \sim 16$ \\
2 & 0.050 & $0 \sim 16$ \\
3 & 0.075 & $0 \sim 16$ \\
4 & 0.100 & $0 \sim 16$ \\
5 & 0.125 & $0 \sim 16$ \\
6 & 0.150 & $0 \sim 16$ \\
7 & 0.175 & $0 \sim 16$ \\
8 & 0.200 & $0 \sim 16$ \\
9 & 0.225 & $0 \sim 16$ \\
10 & 0.250 & $0 \sim 16$ \\
11 & 0.275 & $0 \sim 16$ \\
12 & 0.300 & $0 \sim 16$ \\
13 & 0.325 & $0 \sim 16$ \\
14 & 0.350 & $0 \sim 16$ \\
15 & 0.375 & $0 \sim 16$ \\
16 & 0.400 & $0 \sim 16$ \\
\hline
\end{tabular}

$h_{\mathrm{t}}=0.15, \alpha_{\mathrm{e}}=2^{\circ}$, and when $h_{\mathrm{t}}=0.3, \alpha_{\mathrm{e}}=4^{\circ}$; and when $h_{\mathrm{t}}=0.35, \alpha_{e}=5^{\circ}$. Comparing Figures 6(a) and 6(b) with 6(c), it is found that the pattern of variation of difference of the static pressure with the angle of guiding vane was quite similar at different average air velocities in the tunnel short duct inlet. With the increase of the average air velocity of the short duct inlet, $\Delta p$ decreases at both the same angle of guiding vane and equivalent height. Under the same working conditions, the greater the difference of static pressure between the inlet and outlet of the tunnel is, the higher the pressure-rise of the air outlet will be. Consequently, the air supply outlet pressure-rise reached the maximum when the installation angle of guiding vane was in the range of $2^{\circ} \sim 5^{\circ}$.

3.2. Equivalent Height of Guiding Vane and Pressure-Rise. Figure 7 shows the relationships between $\Delta p$ and $h_{\mathrm{t}}$ for various $\alpha$. It is noted that the average air velocity at the tunnel short duct inlet were $u=1 \mathrm{~m} / \mathrm{s}, 2 \mathrm{~m} / \mathrm{s}$ and $3 \mathrm{~m} / \mathrm{s}$, respectively. As shown in Figure 7 , it is found that when the $h_{\mathrm{t}}$ was less than a certain critical equivalent height $h_{\mathrm{tc}}$, the difference of the static pressure did not change significantly, and the slope of the curve varied gradually. However, when the $h_{\mathrm{t}}$ was greater than the $h_{\mathrm{tc}}$, with the increasing of equivalent height of the guiding vane, the difference of the static pressure changed substantially, and the slope of the curve varied steeply. Meanwhile, $h_{\mathrm{tc}}$ increased with the increase of the installation angle of the guiding vane. Therefore, $h_{\mathrm{tc}}$ does not exist when the angle of the guiding vane was relatively large. For example, as shown in Figure $7(\mathrm{a})$, when $\alpha=4^{\circ}, h_{\mathrm{tc}}$ was about 0.1 ; when $\alpha=10^{\circ}, h_{\mathrm{tc}}$ was about 0.225 ; and when $\alpha=16^{\circ}, h_{\mathrm{tc}}$ was about 0.3 . When the equivalent height of the guiding vane fell in the range of $0<h_{t}<h_{\mathrm{tc}}$, the difference of the static pressure first increased and then decreased, exhibiting a comparably parabolic type of distribution. Comparing Figures 7(a) and 7 (b) with $7(\mathrm{c})$, it is found that, with the increase of the average air velocity at the tunnel short duct inlet, the critical equivalent height $h_{\mathrm{tc}}$ was almost constant if the angle of guiding vane was small (e.g., $\alpha=4^{\circ}$ ). However, with 


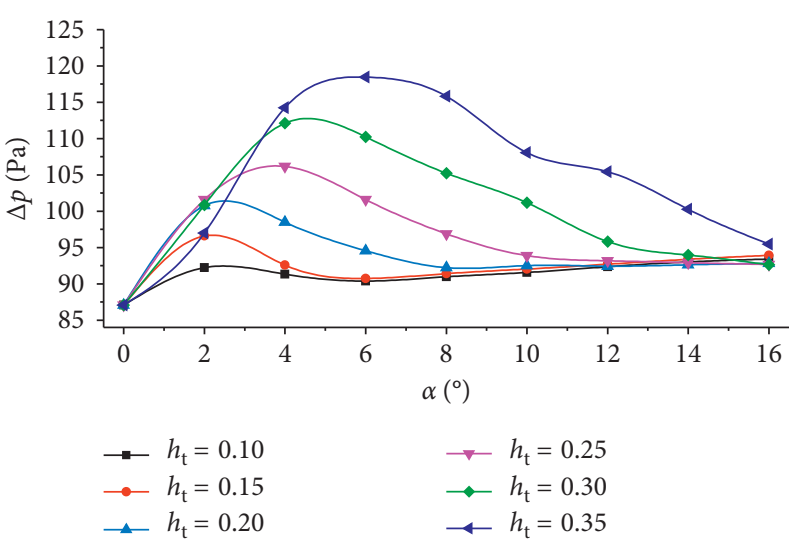

(a)

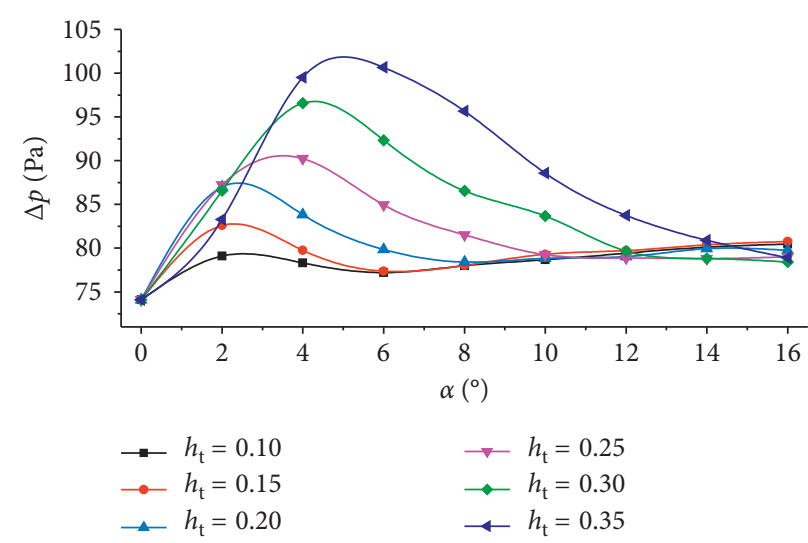

(b)

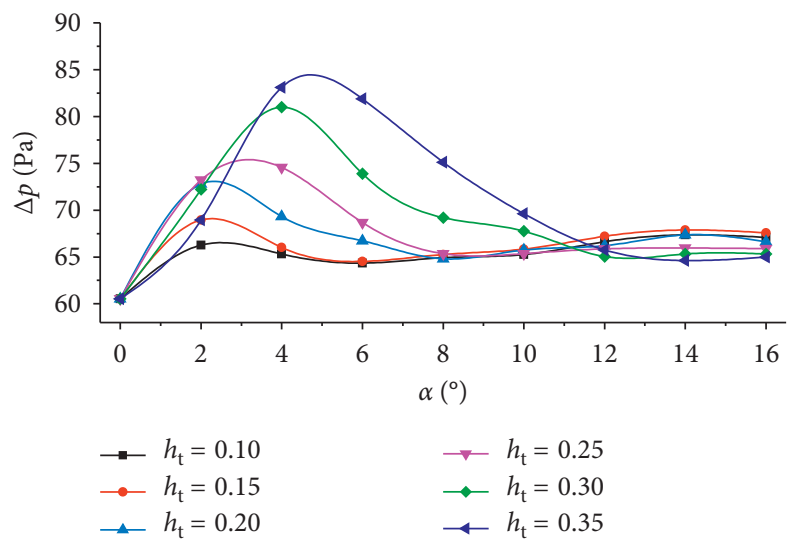

(c)

Figure 6: Curves of static pressure with $\alpha$ for various $h_{\mathrm{t}}$. (a) $u=1 \mathrm{~m} / \mathrm{s}$. (b) $u=2 \mathrm{~m} / \mathrm{s}$. (c) $u=3 \mathrm{~m} / \mathrm{s}$.

the increase of the angle of guiding vane, the change in the difference of the static pressure was more likely affected by the equivalent height. For example, as shown in Figure 7(c), when $\alpha=10^{\circ}, h_{\mathrm{tc}}$ was about 0.3 , while when $\alpha=16^{\circ}$, the equivalent height of the guiding vane was in the range of $0.025 \sim 0.4$, thereby there was no critical equivalent height $h_{\mathrm{tc}}$. Comparing Figures $7(\mathrm{a})$ and $7(\mathrm{~b})$ with $7(\mathrm{c})$, it is also demonstrated that, with the increase of the average air velocity at the tunnel short duct inlet, the difference of the static pressure decreases at the same installation angle and the equivalent height of the guiding vane. Considering the restrictions on the installation height of the guiding vane for highway tunnels, when the installation angle is selected within the range of $2^{\circ} \sim 5^{\circ}$, the optimum equivalent height of the guiding vane is $0.2 \sim 0.35$, and the pressure-rise of air supply outlet will be significantly increased as shown in Figure 6.

3.3. Distribution of Static Pressure. Figure 8 shows the distribution of the static pressure at $X$-axis for the tunnel with $\alpha=4^{\circ}$ and $10^{\circ}$. It is indicated that the pattern of variation of the static pressure at $X$-axis was not affected by the structural parameters of the guiding vane and the average air velocity at the tunnel short duct inlet. Additionally, the pressure-rise increased significantly when the guiding vane was with the optimum structural parameters. From the tunnel short duct inlet to air supply outlet, the change of the static pressure in the tunnel was small. When the distance was within $15 \mathrm{~m}$ (i.e. $X=75 \mathrm{~m}$ ) away from the air supply outlet, the static pressure in the tunnel did not increase rapidly. When the distance was greater than $15 \mathrm{~m}$, the tunnel static pressure rapidly increased. And, it reached the maximum when $X=150 \sim 175 \mathrm{~m}$, and then the static pressure gradually decreased due to the loss of friction resistance along the tunnel. From the distribution of static pressure, it also indicated that the distance required for the pressure-rise was approximately $90 \sim 115 \mathrm{~m}$, and it was not affected by the average air velocity of tunnel short duct inlet and the structure parameters of the guiding vane. Comparing Figures 8 (a) with $8(\mathrm{~b})$, the slope of curves were reduced when the average air velocity of the tunnel short duct inlet increased from $1 \mathrm{~m} / \mathrm{s}$ to $3 \mathrm{~m} / \mathrm{s}$, which demonstrated that the effectiveness of the pressurerise was lowered. Comparing Figures $8(\mathrm{a})$ with $8(\mathrm{c})$, as the installation angle of the guiding vane increased from $4^{\circ}$ to $10^{\circ}$, the slope of curves declined considerably, revealing that the effectiveness of the pressure-rise was reduced significantly.

3.4. Distribution of Streamline. Figure 9 shows the local distribution of streamlines on the $X-Z$ plane of the tunnel 

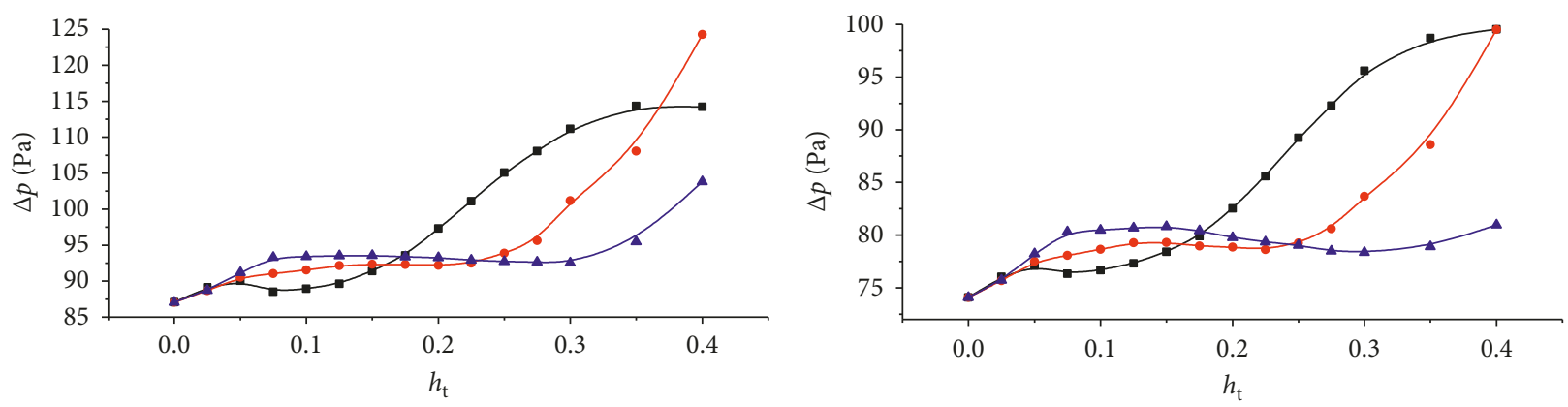

$$
\begin{aligned}
\because \alpha=4^{\circ} & \rightarrow \alpha=4^{\circ} \\
\because \alpha=10^{\circ} & \because \alpha=10^{\circ} \\
\longleftarrow \alpha=16^{\circ} & \rightarrow \alpha=16^{\circ}
\end{aligned}
$$

(a)

(b)

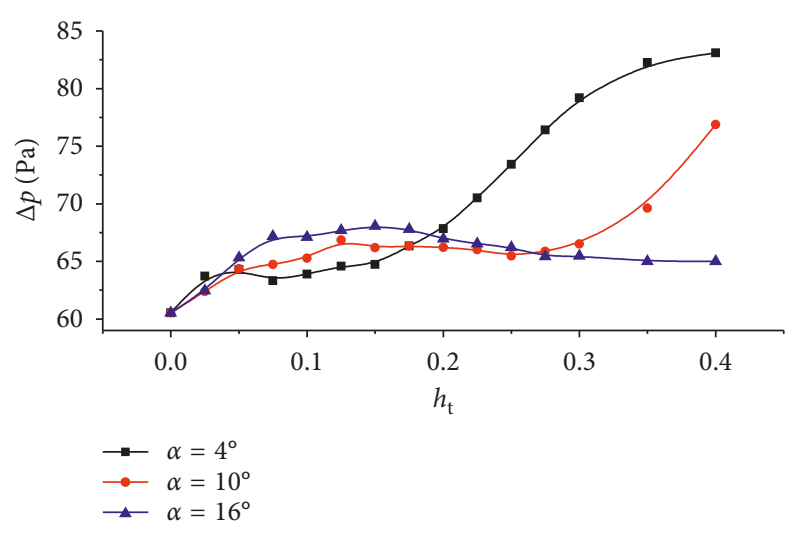

(c)

Figure 7: Curves of static pressure with $h_{\mathrm{t}}$ for various $\alpha$. (a) $u=1 \mathrm{~m} / \mathrm{s}$. (b) $u=2 \mathrm{~m} / \mathrm{s}$. (c) $u=3 \mathrm{~m} / \mathrm{s}$.

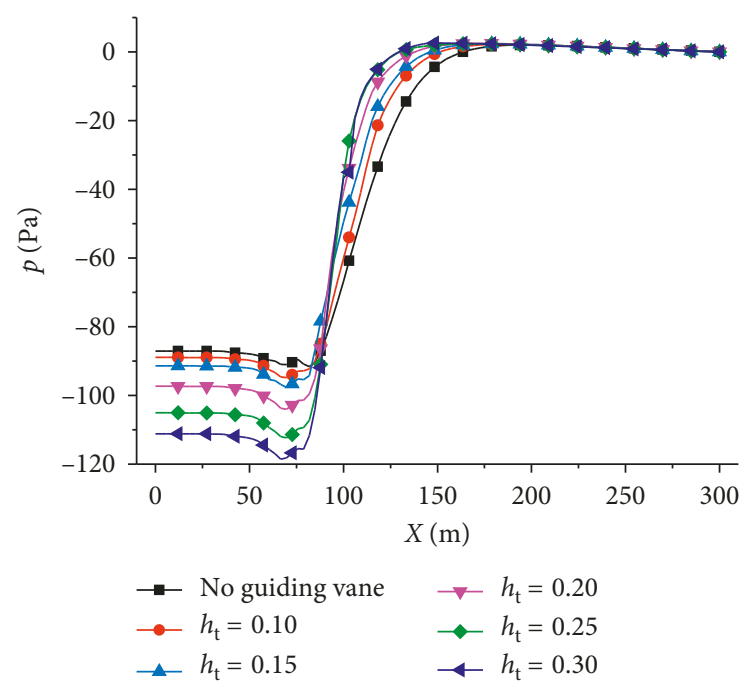

(a)

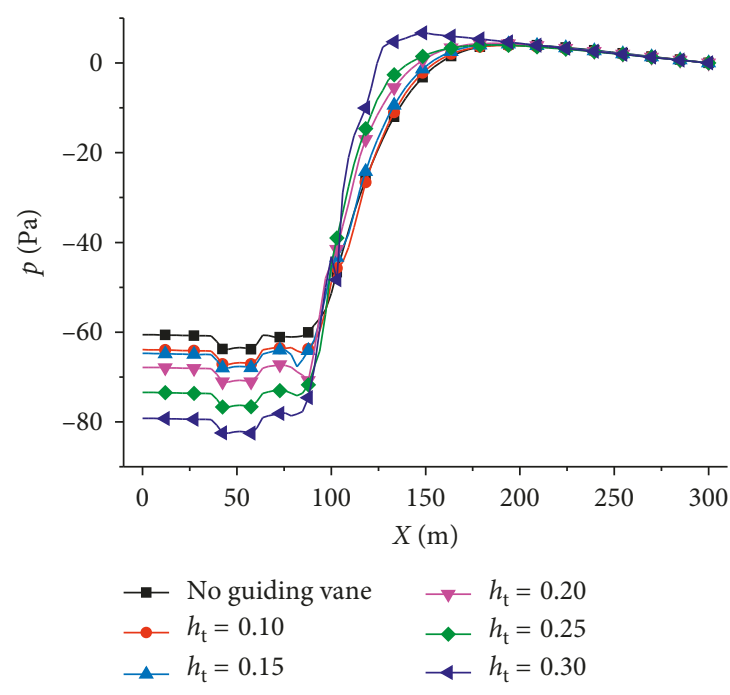

(b)

Figure 8: Continued. 


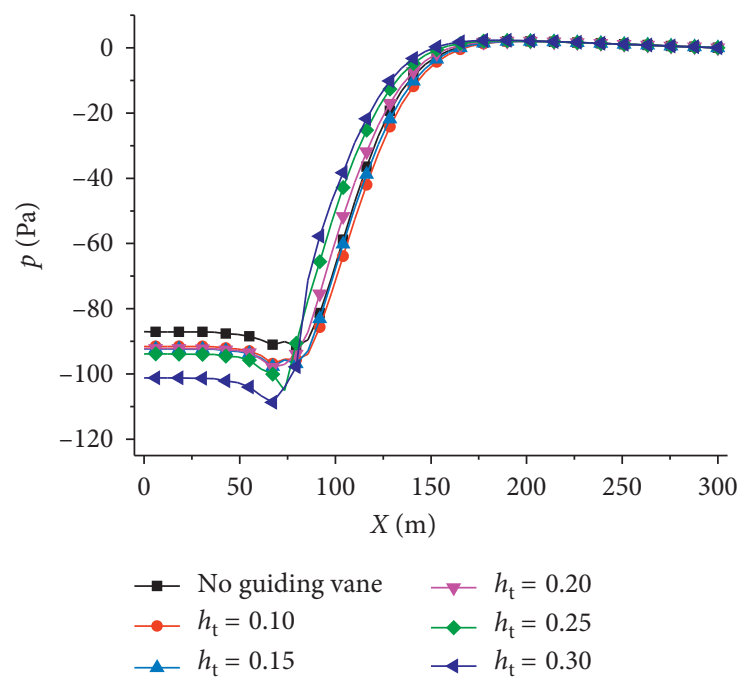

(c)

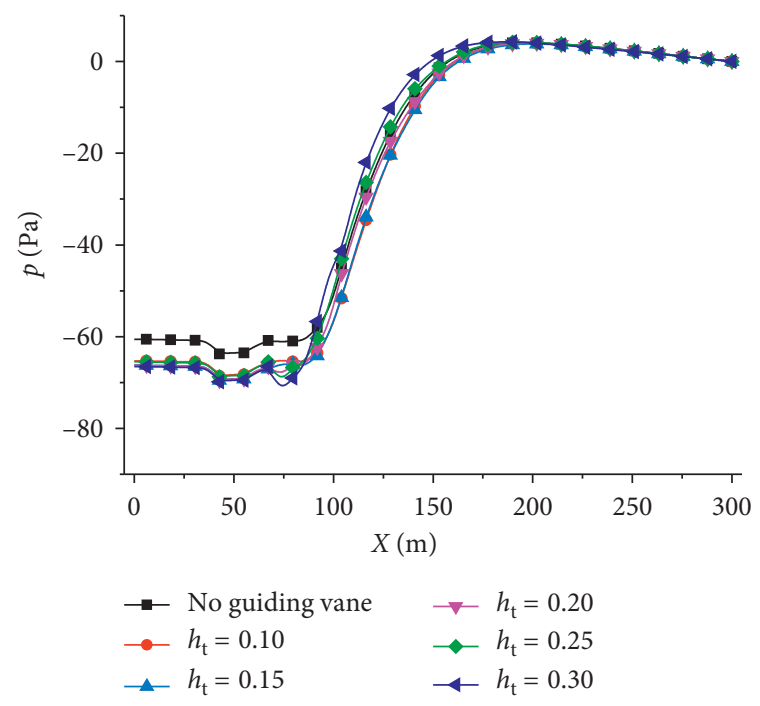

(d)

Figure 8: Static pressure profiles at different positions at $X$-axis. (a) $\alpha=4^{\circ}, u=1 \mathrm{~m} / \mathrm{s}$. (b) $\alpha=4^{\circ}, u=3 \mathrm{~m} / \mathrm{s}$. (c) $\alpha=10^{\circ}, u=1 \mathrm{~m} / \mathrm{s}$. (d) $\alpha=10^{\circ}$, $u=3 \mathrm{~m} / \mathrm{s}$.

with average air velocity of the tunnel short duct inlet $u=1 \mathrm{~m} / \mathrm{s}$. Figure 10 shows the local distribution of streamlines on the $X-Z$ plane of the tunnel with average air velocity of the tunnel short duct inlet $u=1 \mathrm{~m} / \mathrm{s}$ and $Y=0.5 \mathrm{~m}$. In Figures 9 and 10 , it is found that the vortex appeared on both sides of the air outlet in the downstream of the tunnel, which interfered with the flow of fluid in the tunnel and increased the pressure loss in the ventilation system. However, when the guiding vane was set up with the optimum structural parameters, the influencing zone induced by the vortex was minimized. As shown in Figure 9 , before the guiding vane was set up, i.e., $\alpha=0^{\circ}, h_{\mathrm{t}}=0$, the length of the vortex along the tunnel reached $10.5 D_{t}$; when $\alpha=4^{\circ}, h_{\mathrm{t}}=0.300$, it was reduced to $7 D_{\mathrm{t}}$; and when $\alpha=10^{\circ}, h_{\mathrm{t}}=0.300$, it was increased to $9 D_{\mathrm{t}}$. Therefore, by setting up the guiding vane with the optimum structure parameters at the air supply outlet, the vortex effect on the tunnel flow field of the downstream of the air supply outlet can be significantly minimized, and the pressure loss in the ventilation system can be also reduced. Comparing Figure 9 with Figure 10, it is demonstrated that the higher the average air velocity at the tunnel short duct inlet is, the smaller the influencing zone induced by the vortex in the tunnel will be.

3.5. Distribution of Velocity. Figure 11 shows the local distribution of velocity on the $X-Y$ plane with the average air velocity of tunnel short duct inlet $u=1 \mathrm{~m} / \mathrm{s}$. Figure 12 shows the local distribution of velocity on the $X-Y$ plane with the average air velocity of tunnel short duct inlet $u=3 \mathrm{~m} / \mathrm{s}$. In Figure 11, it is found that the air velocity near the dome was relatively high, and there was a negative velocity area in the downstream of the air supply outlet. The existence of the area led to the generation of vortex and energy loss. Also, the friction between the high velocity fluid near the dome and the wall in the tunnel caused energy loss. Comparing Figures 11(a) and 11(b) with $11(\mathrm{c})$, it is indicated that when the guiding vane was set up with the optimum structural parameters, the negative velocity area was minimized, and the velocity at the dome was also greatly decreased. For example, as shown in Figure 11, at $X=105 \mathrm{~m}$, the velocity at dome was about $20 \mathrm{~m} / \mathrm{s}$ (shown in Figure 11(a)), whereas it was $15 \mathrm{~m} / \mathrm{s}$ (shown in Figure 11(b)) and $18 \mathrm{~m} / \mathrm{s}$ (shown in Figure 11(c)). Comparing Figure 11 with Figure 12, the velocity negative area and the average air velocity in the tunnel dome decreased with the increase of average air velocity at the short duct inlet. Hence, the wall friction and the energy loss of the ventilation system can be reduced considerably with the guiding vane set up with the optimum structural parameters.

Figure 13 shows the distribution of velocity at different positions at $Z$-axis with $u=2 \mathrm{~m} / \mathrm{s}, Y=0.5 \mathrm{~m}$. It is noted that $\alpha=0^{\circ}$ referred to the condition without the guiding vane. As shown in Figure 13, the velocity was symmetrically distributed along the $Z$-axis, and the velocity was close to zero near both sides of the tunnel wall. Without the guiding vane (shown in Figure 13(a)), at the early stage of development of jet, such as $X=80 \mathrm{~m}$, due to the entrainment effect from the high velocity jet near the tunnel dome, the velocity distribution of the low velocity fluid in the tunnel short duct fluctuated and reached two minimum values on both sides of the tunnel. It is because the backflow of the downstream of air supply outlet caused an increase in the velocity near the wall of the tunnel. With the further interaction of the two fluids, at $X=100 \mathrm{~m}$, the velocity in the center of the tunnel decreased significantly to the minimum, and even smaller than that at the short duct inlet, which indicated that the backflow effect was more prominent. At the later stage of the development of 

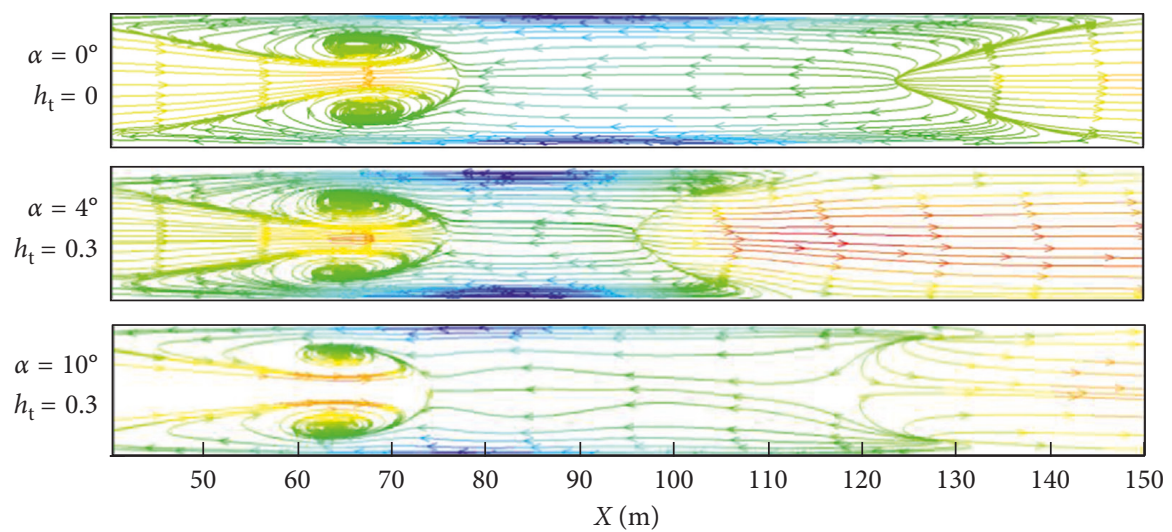

Figure 9: Local streamline distribution on $X-Z$ plane for $u=1 \mathrm{~m} / \mathrm{s}$ and $Y=0.5 \mathrm{~m}$.
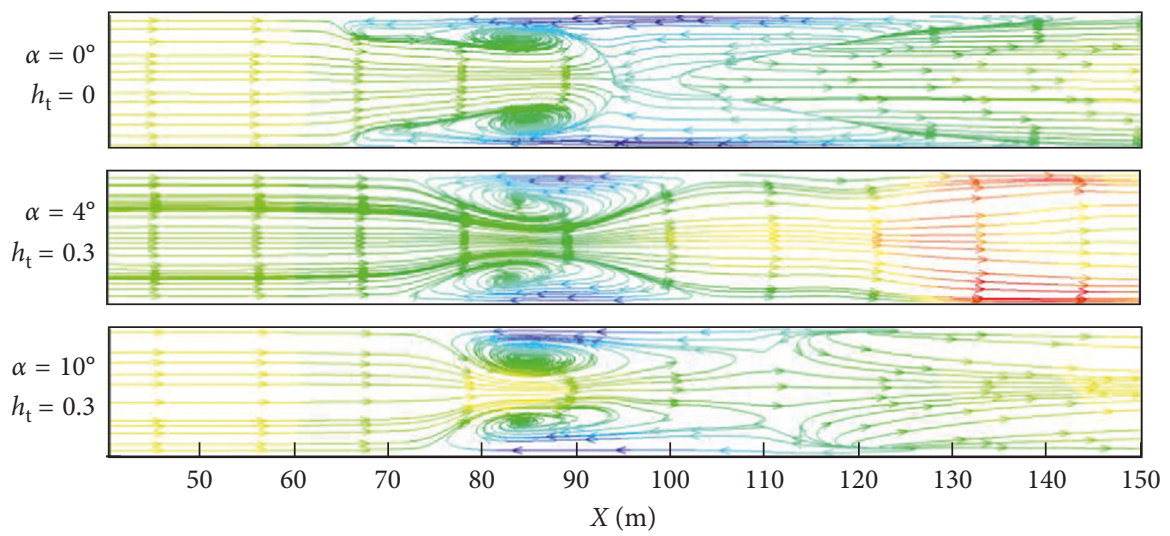

FIgUre 10: Local streamline distribution on $X-Z$ plane for $u=3 \mathrm{~m} / \mathrm{s}$ and $Y=0.5 \mathrm{~m}$.

the jet, the velocity in the center of the tunnel gradually increased, and it was parabolically distributed with respect to the $Z$-axis. Subsequently, the velocity distribution gradually became stable. When the guiding vane was set up, $\alpha=4^{\circ}, h_{\mathrm{t}}=0.3$, as shown in Figure $13(\mathrm{~b})$, the velocity disturbance zone was significantly reduced, and the velocity distribution was more stable in the area. At $X=100 \mathrm{~m}$, the velocity in the center of the tunnel had a small change, and the extremum corresponding to the minimum velocity shifted to both sides. At $X=120 \mathrm{~m}$, the minimum velocity disappeared. With the increase of the installation angle of the guiding vane, the velocity disturbance zone by the jet gradually increased as shown in Figure 13(c). Therefore, it is demonstrated that the air velocity in the tunnel tends to be more stable, which not only reduces the disturbance zone of the flow field induced by the jet but also reduces the energy loss.

\section{Conclusions}

In this study, a local 3D physical model was proposed for the shaft blowing and exhausting longitudinal ventilation for highway tunnel. A guiding vane was proposed to set up on the tunnel dome at the downstream of the air supply outlet to change the characteristics of flow field. CFD approach was also used to simulate the effects of installation angle and height of the guiding vane on the ventilation systems. Main conclusions from this study can be drawn as the follows:

(1) By setting up the guiding vane with the optimum structural parameters at the downstream of the air supply outlet, the effects from the vortex and the air velocity of the dome wall were significantly minimized, which was found to play a significant role in drag reduction.

(2) Under the same working conditions, the greater the difference of the static pressure between the inlet and outlet is, the greater the pressure-rise of the air outlet will be. It is concluded that the optimum installation angle of the guiding vane was in the range of $2^{\circ} \sim 5^{\circ}$, and the optimum equivalent height of the guiding vane was in the range of $0.2 \sim 0.35$. With the optimum structural parameters of the guiding vane, the frictional loss and vortex loss in tunnel were greatly reduced, leading to a substantial reduction of the energy loss in the ventilation system. 


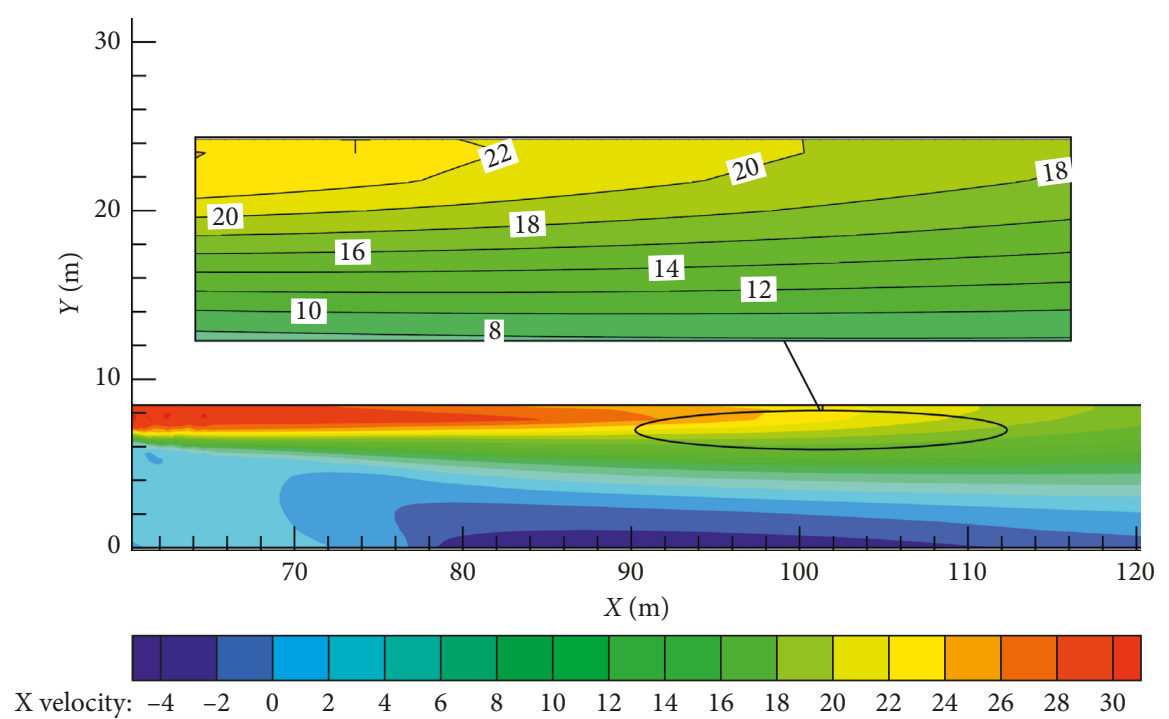

(a)
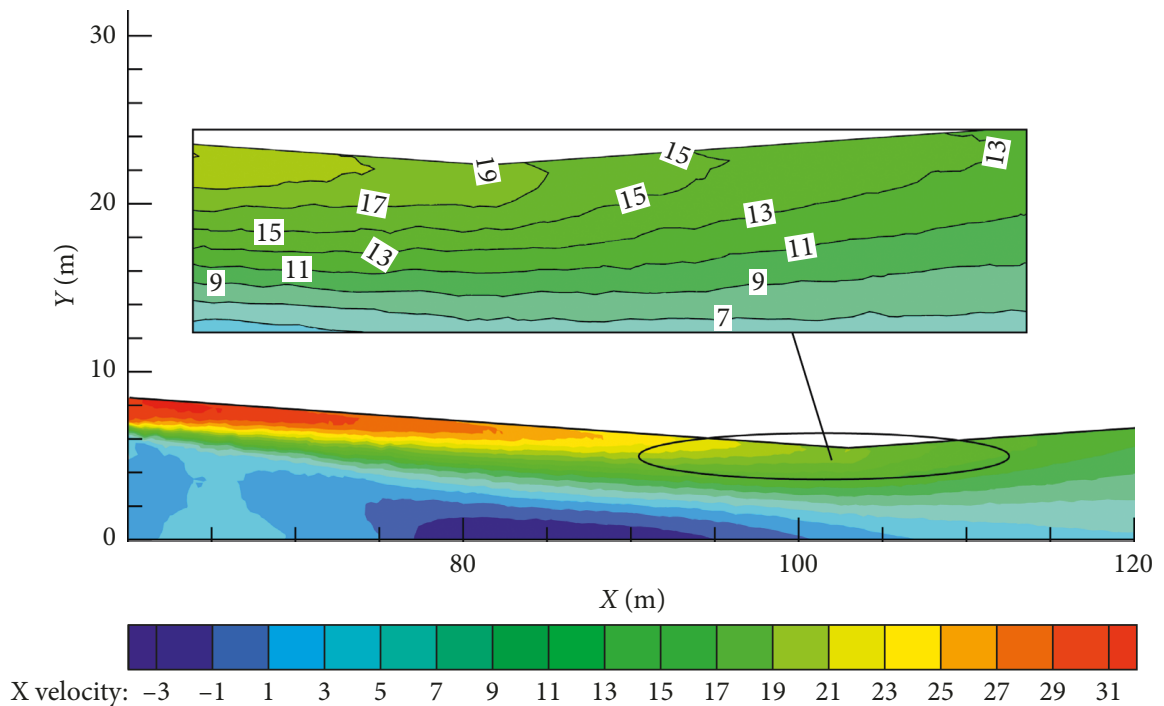

(b)
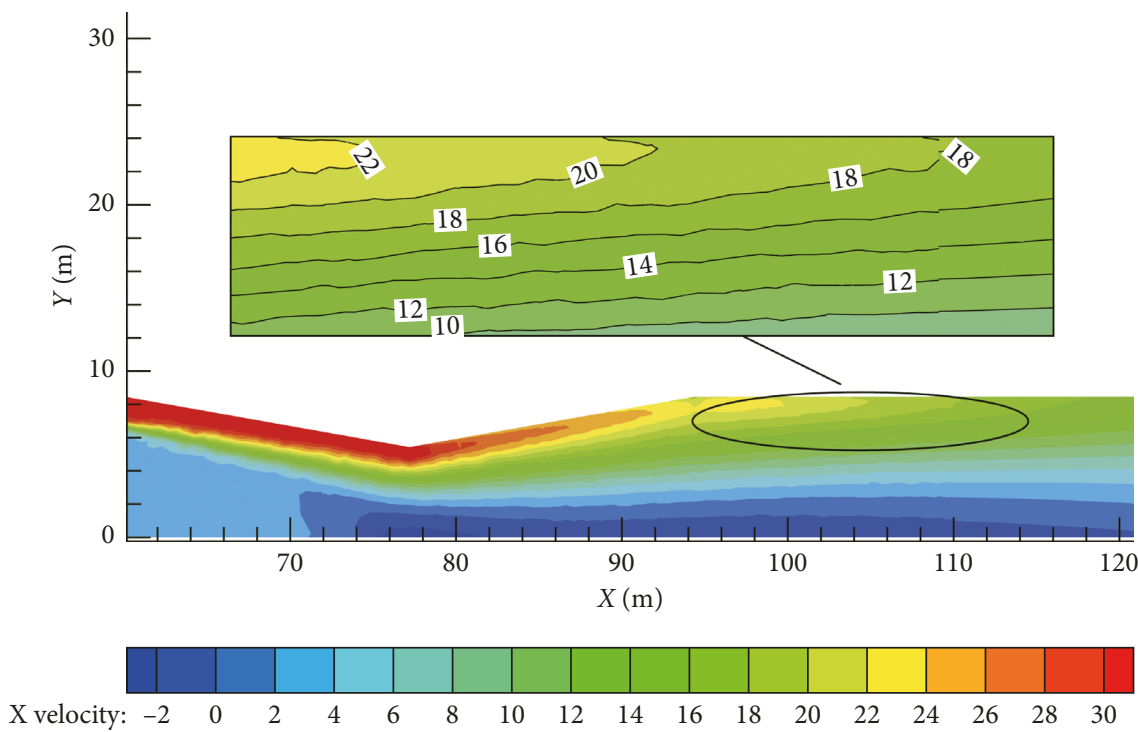

(c)

Figure 11: Local velocity distribution on $X-Y$ plane for $u=1 \mathrm{~m} / \mathrm{s}$ and $Z=0 \mathrm{~m}$. (a) $\alpha=0^{\circ}$. (b) $\alpha=4^{\circ}$. (c) $\alpha=10^{\circ}$. 


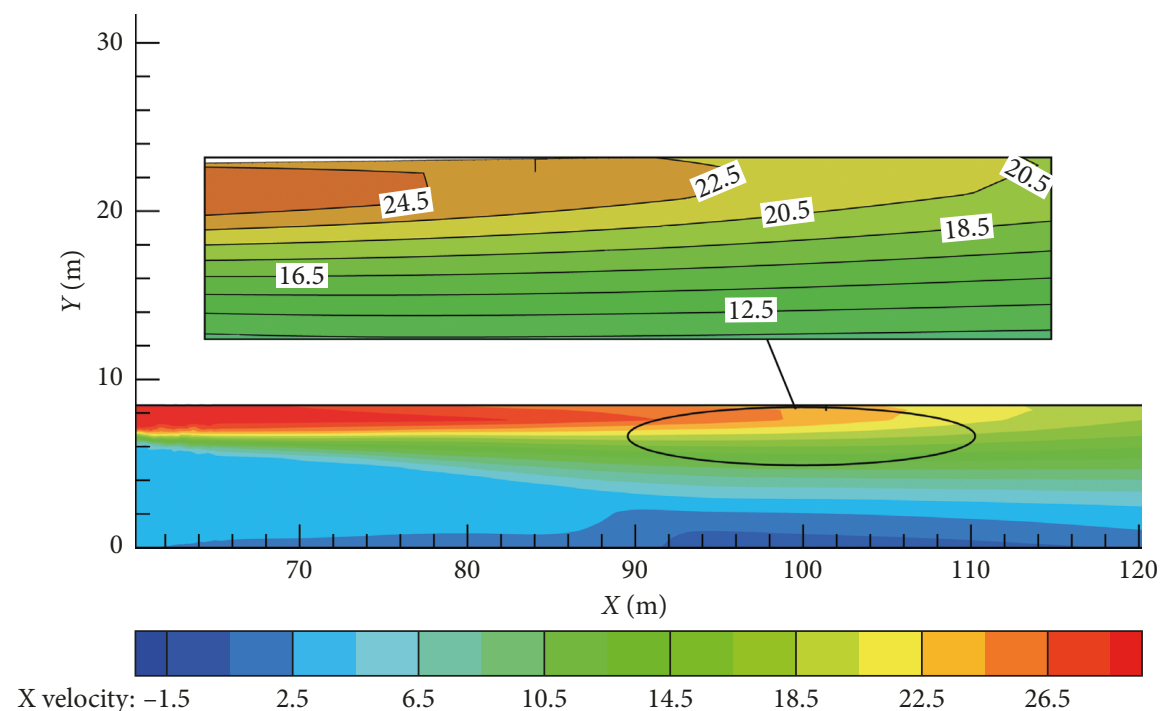

(a)

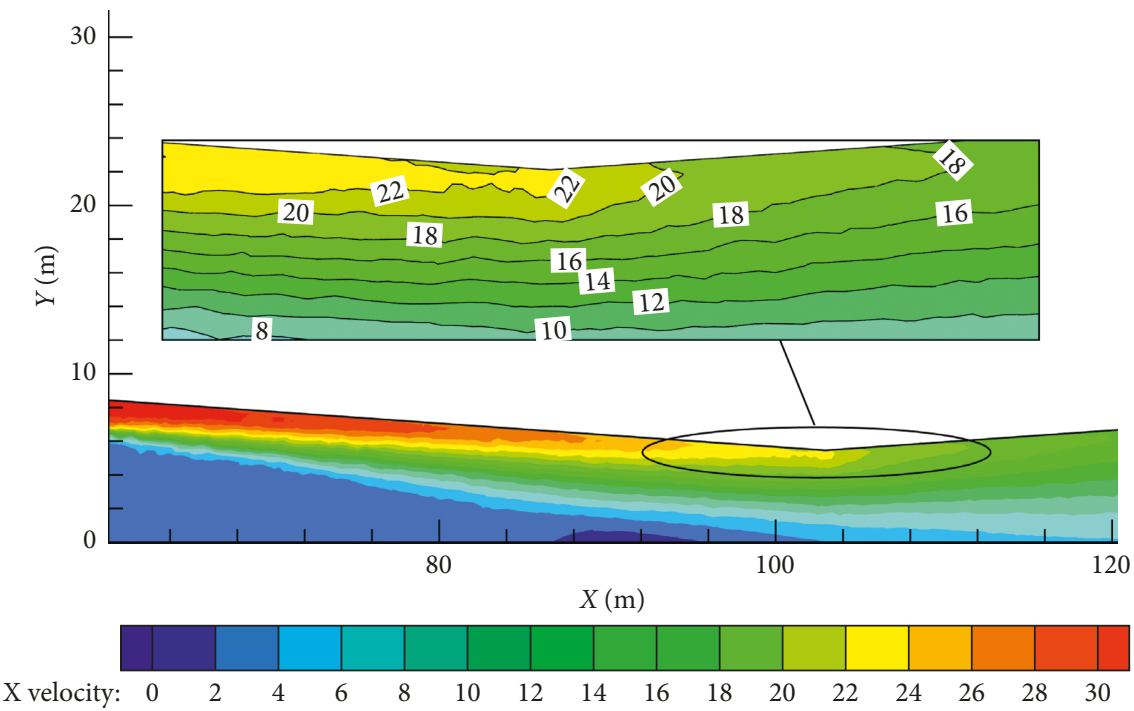

(b)

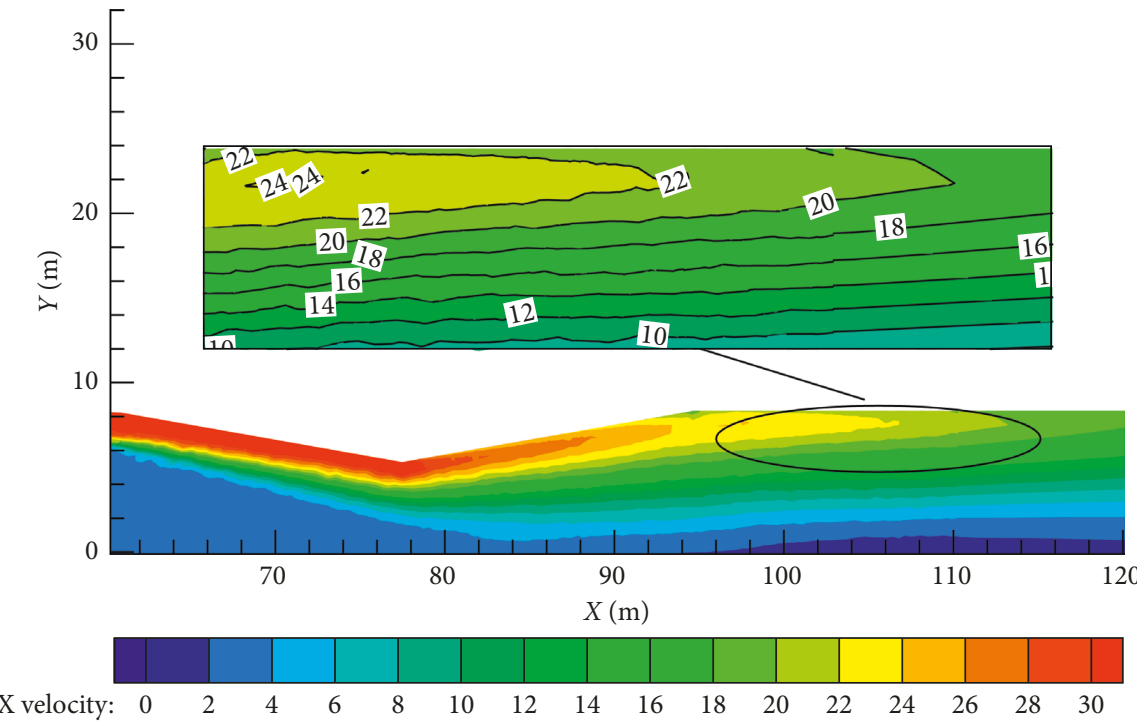

(c)

Figure 12: Local velocity distribution on $X-Y$ plane for $u=3 \mathrm{~m} / \mathrm{s}$ and $Z=0 \mathrm{~m}$. (a) $\alpha=0^{\circ}$. (b) $\alpha=4^{\circ}$. (c) $\alpha=10^{\circ}$. 


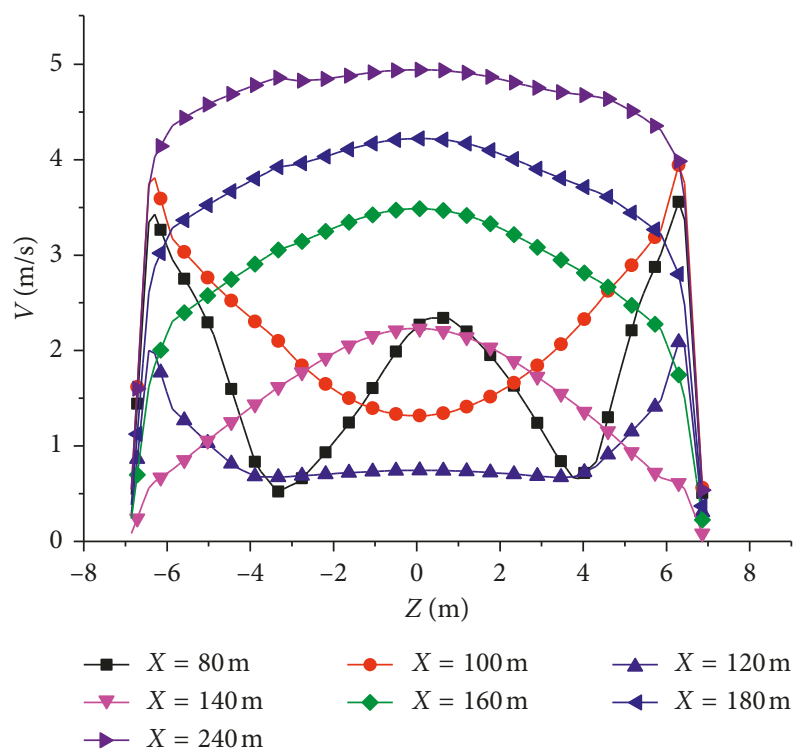

(a)

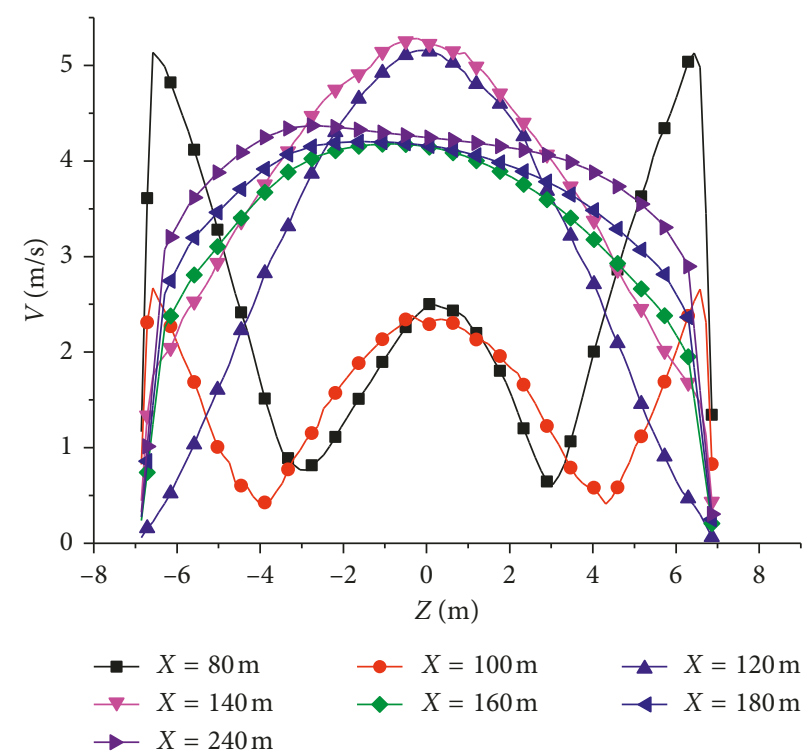

(b)

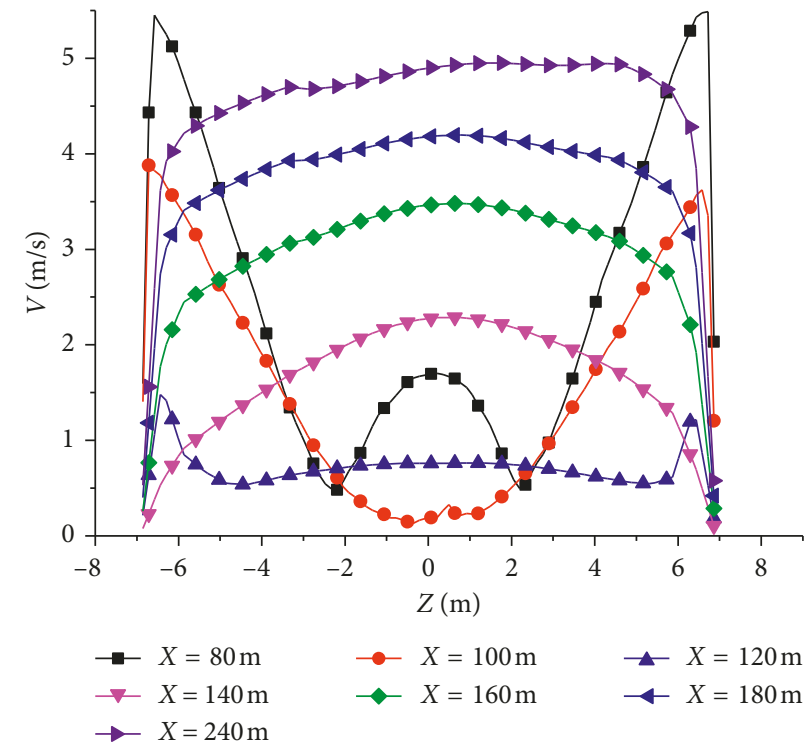

(c)

FigURE 13: Velocity distribution at different positions at $Z$ axial for $u=2 \mathrm{~m} / \mathrm{s}$ and $Y=0.5 \mathrm{~m}$. (a) $\alpha=0^{\circ}, h_{\mathrm{t}}=0$. (b) $\alpha=4^{\circ}, h_{\mathrm{t}}=0.3$. (c) $\alpha=10^{\circ}$, $h_{\mathrm{t}}=0.3$.

(3) The required distance for the pressure-rise was approximately $90 \sim 115 \mathrm{~m}$, and it is not affected by the average air velocity in the tunnel short duct inlet and the structural parameters of the guiding vane.

\section{Data Availability}

The data used to support the findings of this study are available from the corresponding author upon request.

\section{Conflicts of Interest}

The authors declare that there are no conflicts of interest regarding the publication of this paper.

\section{Acknowledgments}

The authors are grateful for the financial support received from the National Natural Science Foundation of China (Grant Nos. 51474105, 51864014 and 51774134), the Project of Scientific Research Fund of the Hunan Provincial Education Department (Grant No. 16B094), and the Open Research Fund Program of Work Safety Key Lab on Prevention and Control of Gas and Roof Disasters for Southern Coal Mines (Hunan University of Science and Technology, Grant No. E21824).

\section{References}

[1] C. Guo, M. N. Wang, L. Yang, Z. Sun, Y. Zhang, and J. Xu, “A review of energy consumption and saving in extra-long tunnel 
operation ventilation in China," Renewable and Sustainable Energy Reviews, vol. 53, no. 6, pp. 1158-1569, 2016.

[2] X. J. Tan, W. Z. Chen, Y. G. Dai et al., "Experimental research on the mixture mechanism of polluted and fresh air at the portal of small-space road tunnels," Tunnelling and Underground Space Technology incorporating Trenchless Technology Research, vol. 50, pp. 118-128, 2015.

[3] J. Šulc, L. Ferkl, J. Cigler, and J. Pořízek, "Optimization-based control of ventilation in a road tunnel complex," Control Engineering Practice, vol. 69, pp. 141-155, 2017.

[4] J. H. Kim, J. H. Kim, K.-Y. Kim, J.-Y. Yoon, S.-H. Yang, and Y.-S. Choi, "High-efficiency design of a tunnel ventilation jet fan through numerical optimization techniques," Journal of Mechanical Science and Technology, vol. 26, no. 6, pp. 17931800, 2012.

[5] M. Ishida, "Jet fan for road tunnel ventilation systems. Pressure rise and diffusion of jet," Transactions of the Japan Society of Mechanical Engineers Part B, vol. 57, no. 533, pp. 115-120, 1991.

[6] G. Pavesi, A. D. Martegani, and C. Barbetta, "Experimental study on the longitudinal ventilation system," in Proceedings of the 8th International Symposium on Aerodynamics and Ventilation of Vehicle Tunnels, Liverpool, UK, July 1994.

[7] V. Betta, F. Cascetta, M. Musto, and G. Rotondo, "Numerical study of the optimization of the pitch angle of an alternative jet fan in a longitudinal tunnel ventilation system," Tunnelling and Underground Space Technology, vol. 24, no. 2, pp. 164172, 2009.

[8] V. Betta, F. Cascetta, M. Musto, and G. Rotondo, "Fluid dynamic performances of traditional and alternative jet fans in tunnel longitudinal ventilation systems," Tunnelling and Underground Space Technology, vol. 25, no. 4, pp. 415-422, 2010.

[9] S. C. Lee, S. Lee, and J. Lee, "CFD analysis on ventilation characteristics of jet fan with different pitch angle," KSCE Journal of Civil Engineering, vol. 18, no. 3, pp. 812-818, 2014.

[10] J. G. Fan, Y. Fang, and S. Lei, "Research on the layout of jet fans in two-lane highway tunnels," Modern Tunneling Technology, vol. 54, no. 2, pp. 149-155, 2017.

[11] F. Wang, M. N. Wang, and Y. Y. Deng, "Research on optimal distribution of jet fans in curvy tunnel," Journal of Highway and Transportation Research and Development, vol. 26, no. 5, pp. 86-90, 2009.

[12] F. Wang, M. N. Wang, S. He, J. Zhang, and Y. Deng, "Computational study of effects of jet fans on the ventilation of a highway curved tunnel," Tunnelling and Underground Space Technology, vol. 25, no. 4, pp. 382-390, 2010.

[13] F. Wang, M. N. Wang, and Q. Wang, "Numerical study of effects of deflected angles of jet fans on the normal ventilation in a curved tunnel," Tunnelling and Underground Space Technology incorporating Trenchless Technology Research, vol. 31, no. 5, pp. 80-85, 2012.

[14] P. Shi and Y. X. Xia, "Numerical analysis and optimization research of short duct flow field of outlet and inlet in highway tunnel," Chinese Journal of Underground Space and Engineering, vol. 5, no. 2, pp. 402-405, 2009.

[15] X. Zhang, T. H. Zhang, Z. Y. Huang, and K. Wu, "Local loss and flow characteristic of dividing flow in bifurcated tunnel," Journal of Zhejiang University (Engineering Science), vol. 52, no. 3, pp. 440-445, 2018.

[16] F. Li, Y. X. Xia, and C. F. Gou, "Study on the design optimization of bending-duct in road tunnel," Chinese Journal of Underground Space and Engineering, vol. 10, no. 2, pp. 455459, 2014.
[17] Ministry of Communications of the PRC, JTJ/T D70/2-022014 Guidelines for Design of Ventilation of Highway Tunnels, People's Communications Publishing House, Beijing, China, 2014.

[18] J. Y Jung, S. G Kang, H. J. Yoon, K. B. Shin, and J.-K. Lee, "Analysis of heat and smoke flow according to platform screen door and fan conditions on fire in underground platform," Advances in Civil Engineering, vol. 2018, Article ID 4803058, 8 pages, 2018.

[19] F. Wang, M. N. Wang, and S. He, "Computational study of effects of traffic force on the ventilation in highway curved tunnels," Tunnelling and Underground Space Technology, vol. 26, no. 3, pp. 481-489, 2011.

[20] E. Eftekharian, A. Dastan, O. Abouali, J. Meigolinedjad, and G. Ahmadi, "A numerical investigation into the performance of two types of jet fans in ventilation of an urban tunnel under traffic jam condition," Tunnelling and Underground Space Technology, vol. 44, no. 3, pp. 56-67, 2014. 


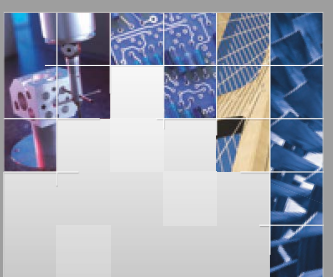

\section{Enfincering}
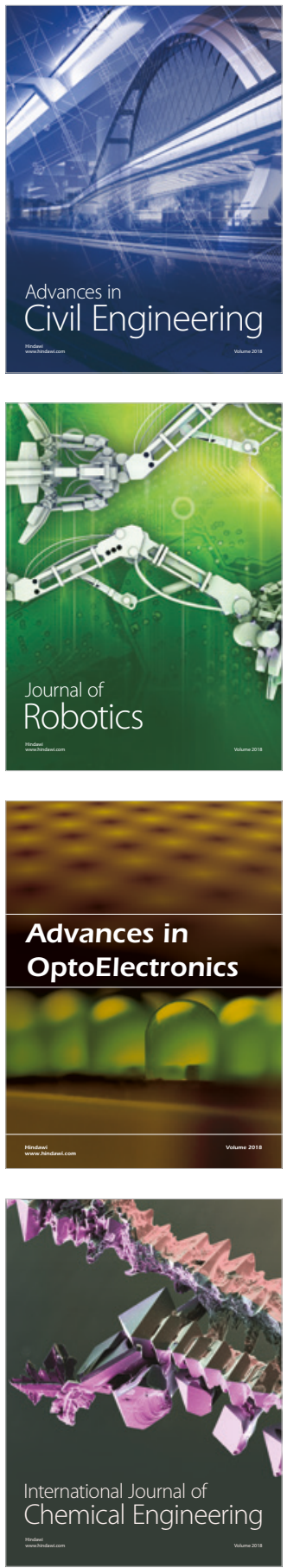

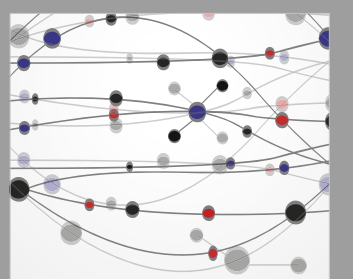

\section{Rotating \\ Machinery}

The Scientific World Journal

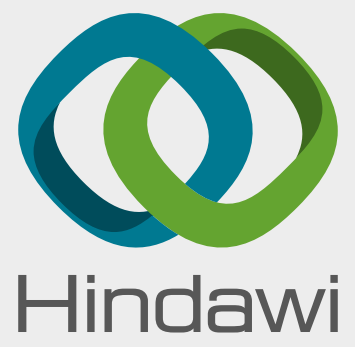

Submit your manuscripts at

www.hindawi.com
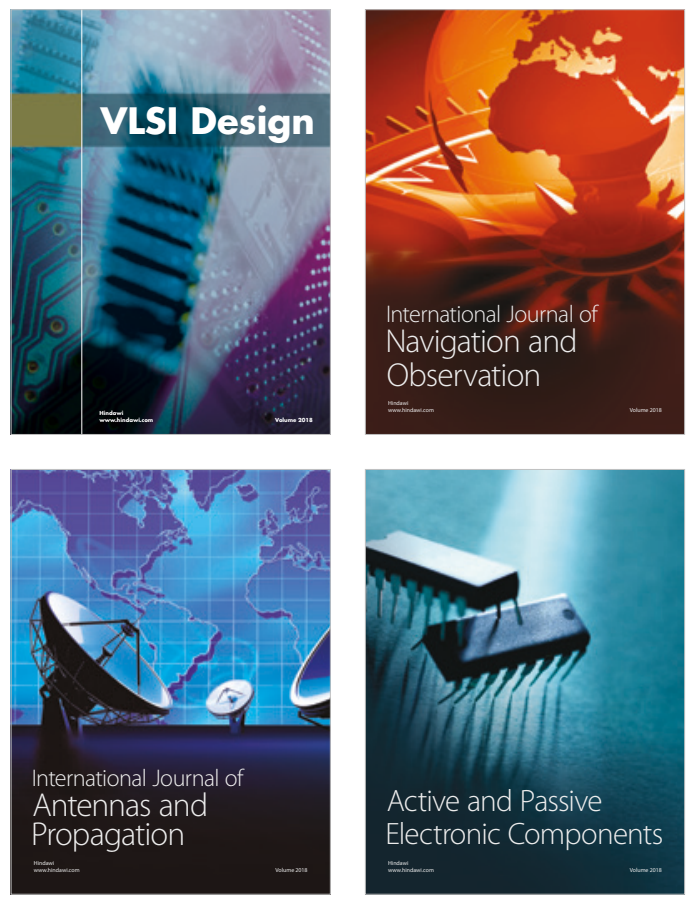
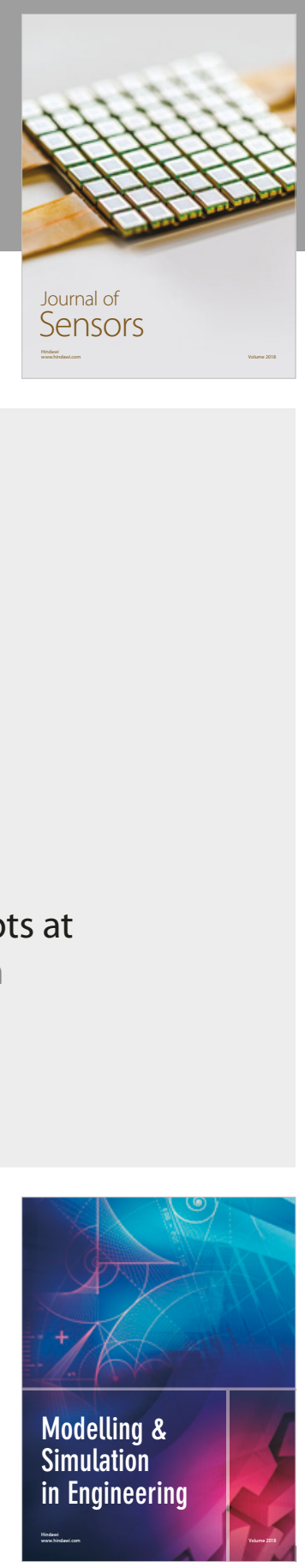

\section{Advances \\ Multimedia}
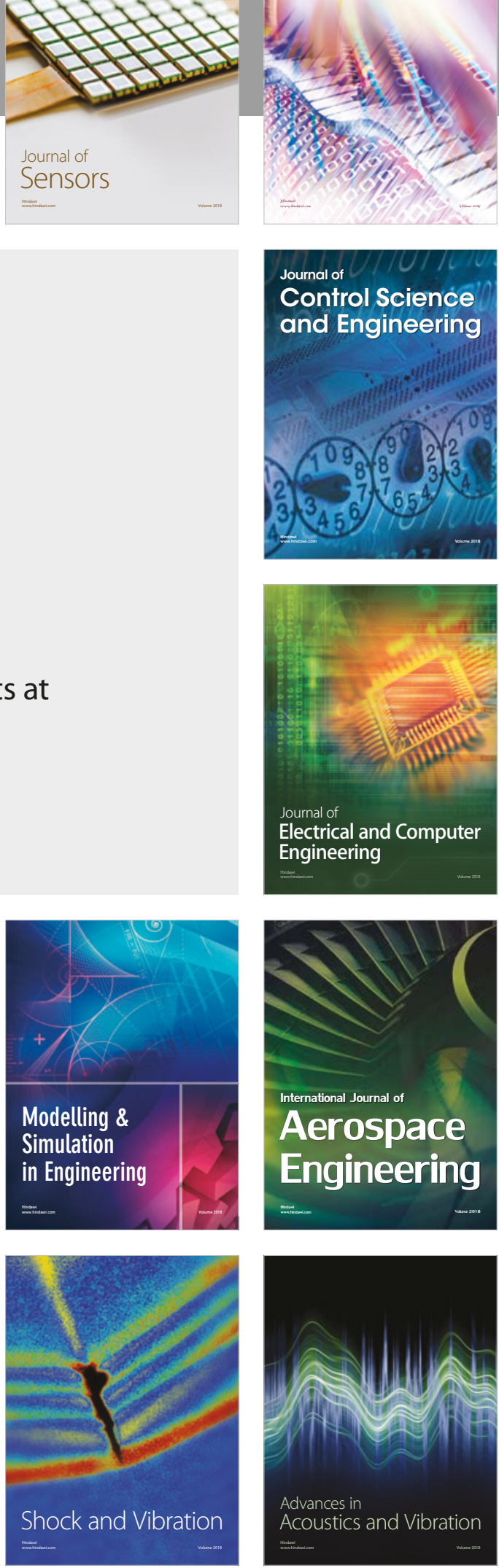